\title{
STUDI SUMBER PENYEBAB TERJADINYA KEBAKARAN DAN RESPON MASYARAKAT DALAM RANGKA PENGENDALIAN KEBAKARAN HUTAN GAMBUT DI AREAL MAWAS KALIMANTAN TENGAH
}

\author{
(Study of fire sources and community respond for peat swamp forest fire control in Mawas \\ area Central Kalimantan)
}

\author{
Acep Akbar ${ }^{1)}$, Sumardi ${ }^{2)}$, Ris Hadi, Purwanto ${ }^{2)}$ dan/and M. Sambas Sabarudin ${ }^{2)}$ \\ ${ }^{1)}$ Balai Penelitian Kehutanan Banjarbaru, ${ }^{2)}$ Fakultas Kehutanan, Universitas Gadjah Mada \\ ${ }^{1)} \mathrm{Jl}$. Ahmad Yani Km. 28,7 Landasan Ulin, Banjarbaru \\ Telp./Fax. 0511-4707872 \\ ${ }^{2)} \mathrm{Jl}$. Bulaksumur, Yogyakarta
}

Naskah masuk : 5 Januari 2011; Naskah diterima : 7 November 2011

\begin{abstract}
Fire prevention activity in peat swamp forest might have supported by a continually knowledge of user in the field. As well as for be a guidance for preventing offire. This knowledge can constructing achievement suitable target. Public opinion about innovation necessary to study for compromise between government and local people to formulate the reliable fire prevention method, hence innovative diffusion will be proceed quickly. Public opinion survey at five villages in the vicinity of Mawas Konservation Forest, resulted a routine fire come from arable land farmer and fisherman, while incidentally fire come from rattan farmer, illegal logger, gold mineworker, and boat maker. Fire prevention activity that were responsived well by society are education patterns and applied technology of fire prevention, except implementation of zero burning agriculture and agroforestry planting system. In short, colaboration between government and forest dwelling especially arable land farmer and fishermen in fire prevention tend to decrease forest fire insident.
\end{abstract}

Keyword: Land fire source, Fire prevention, Peat swamp forest

\begin{abstract}
ABSTRAK
Aktivitas pencegahan kebakaran hutan rawa gambut perlu didasari oleh adanya pengetahuan tentang profil manusia pengguna api rutin di lahan yang identik dengan sumber-sumber api pemicu kebakaran. Pengetahuan tersebut berguna untuk mengarahkan pembinaan pencegahan kebakaran yang dilakukan oleh pemerintah sehingga tepat sasaran. Respon masyarakat terhadap jenis-jenis inovasi pencegahan kebakaran yang diterapkan perlu digali agar tercipta peluang kolaborasi antara pihak pemerintah atau pengelola dengan masyarakat target sehingga proses peningkatan kesadaran, kesiagaan dan difusi inovasi dapat berjalan secara cepat. Melalui penelitian survey opini publik di lima desa contoh sekitar hutan konservasi Mawas di Kalimantan Tengah diketahui bahwa sumber api rutin berasal dari petani ladang dan penangkap ikan, sedangkan pengguna api lain bersifat tidak rutin yaitu petani rotan, pencari rotan, pencari kulit gemor, dan pencari madu, pengayu, penambang emas, dan pengrajin perahu klotok. Kegiatan pencegahan yang mendapat respon masyarakat adalah semua pola penyuluhan dan penerapan teknologi yang umum dilakukan dalam pencegahan kebakaran kecuali persiapan lahan tanpa bakar dan pola tanam agroforestry. Disimpulkan bahwa aktivitas pencegahan kebakaran jika dilakukan melalui kolaborasi antara pemerintah dengan masyarakat sekitar hutan terutama dengan petani ladang dan penangkap ikan berpotensi menurunkan frekuensi terjadinya kebakaran.
\end{abstract}

Kata kunci: Hutan rawa gambut, pencegahan kebakaran, sumber kebakaran lahan 


\section{PENDAHULUAN}

\section{A. Latar Belakang}

Hasil penelitian menunjukkan bahwa kebakaran yang terlanjur besar sangat sulit dipadamkan sekalipun menggunakan peralatan pemadam berteknologi tinggi. Api hanya padam setelah bahan bakar habis (Heikkila et al, 1993). Chandler et al. (1983) mengatakan bahwa pengetahuan sumber api merupakan faktor kunci dalam meningkatkan keberhasilan pencegahan kebakaran. Bila sumber-sumber penyebab kebakaran diketahui maka akan mudah dilakukan kegiatan (Chandler et al, 1983; Suratmo et al, 2003). Peristiwa kebakaran pada umumnya sangat sulit dibuktikan karena selalu dimulai dengan adanya api kecil yang berawal dari kelalaian pengguna api rutin saat pembakaran lahan, peristiwa yang bersifat insidentil seperti pembakaran akibat tujuan kriminal, puntung rokok, dan peristiwa alam. Data hotspot dari citra satelit NOAA-AVHR dapat menunjukkan kejadian kebakaran di suatu tempat (Saharjo, 2004), tetapi belum bisa menentukan profil manusia mana yang menjadi pemicu insiden kebakaran tersebut.

Sumber api dihasilkan oleh profil manusia yang dalam matapencahariannya selalu menggunakan api sehingga sumber api tersebut bersifat rutin. Penyuluhan sangat diperlukan dalam rangka meningkatkan kesadaran melakukan pencegahan, memperoleh pengetahuan kerugian akibat kebakaran serta menentukan pola kolaborasi pencegahan kebakaran dengan masyarakat sekitar hutan. Arah dan sasaran penyuluhan akan lebih tepat jika ditujukan kepada masyarakat pengguna api lahan secara langsung. Oleh karena itu pertanyaan yang timbul adalah bagaimana cara memperoleh pengetahuan tentang profil-profil manusia yang diyakini sebagai pengguna api lahan secara rutin. Jenis-jenis kerjasama apa yang dapat dijalin antara pemerintah dengan masyarakat sekitar hutan yang diindikasikan oleh komitmen masyarakat dalam menerima jenis-jenis aktivitas pencegahan kebakaran yang ditawarkan.

Masyarakat sekitar hutan seyogyanya memiliki pengetahuan tentang profil-profil manusia pengguna api rutin setiap tahun di lingkungan komunitas desanya dan yang mengetahui lebih awal api liar yang terjadi serta memiliki juga rasa ketertarikan dengan pola-pola pencegahan kebakaran tertentu baik yang akan maupun yang sudah dilakukan oleh pemerintah. Rasa ketertarikan biasanya timbul karena cara baru tentang sesuatu dipandang sangat praktis dan efektif oleh kalangan masyarakat. Peran masyarakat sekitar hutan sangat penting dalam pengelolaan kebakaran karena selain mereka dapat berperan sebagai penyebab juga dapat berperan sebagai pencegah dan pemadam api awal sebelum api besar (Marbyanto, 2003).

Strategi manajemen kebakaran hutan berbasis masyarakat telah menjadi solusi alternatif khususnya di negara-negara Afrika dan Asia dengan harapan agar bencana kebakaran dalam skala luas dapat dicegah (Karki, 2002). Salah satu kebutuhan dalam menerapkan pencegahan kebakaran berbasis masyarakat adalah pendidikan dan penyuluhan (Moore dan Haase, 2002). Topik penyuluhan dan pendidikan yang diperlukan masyarakat adalah pendidikan lingkungan dan kebakaran hutan, penerapan teknologi pencegahan kebakaran, dan sosialisasi peraturan yang berhubungan dengan kebakaran hutan dan lahan.

Salah satu cara untuk menselaraskan antara minat pemerintah dengan minat masyarakat dalam hal pencegahan kebakaran adalah dengan cara menawarkan jenis-jenis aktivitas pencegahan yang telah umum dilakukan kepada masyarakat. Dalam upaya mengetahui adanya pilihan yang dapat merepresentasikan kehendak masyarakat diperlukan suvey opini publik (public opinion survey) pada masyarakat sasaran. Dengan cara demikian, inovasi-inovasi pencegahan sebagai bahan pembinaan kepada masyarakat akan sesuai dengan keinginan masyarakat sekitar hutan sehingga dapat mempercepat proses difusi inovasi. Hipotesis deskriptif yang muncul adalah bahwa masyarakat memiliki pengalaman dan pengetahuan lokal tentang sumber-sumber api rutin setiap tahun di masing-masing desanya sehingga pemikiran-pemikiran baru diperlukan agar tradisi negatif yang berkembang di masyarakat desa.dapat diperbaiki menuju arah lingkungan yang aman dan tertib khususnya dalam hal menggunakan api lahan.

\section{B. Tujuan Penelitian}

Tujuan penelitian ini adalah untuk menganalisis sumber penyebab terjadinya kebakaran dan peluang kolaborasi dalam pengendalian kebakaran berdasarkan pendapat masyarakat tentang pola-pola penyampaian inovasi yang tepat dalam penyuluhan dan penerapan teknologi sederhana di masyarakat sehingga meningkatkan efektivitas pencegahan kebakaran hutan dan lahan. 


\section{METODE PENELITIAN}

\section{A. Waktu dan Lokasi Penelitian}

Penelitian dilakukan dari bulan November 2009 sampai dengan Januari 2010 di kawasan hutan konservasi Mawas yang merupakan bagian dari kawasan eks PLG (Proyek Pengembangan Lahan Gambut). Kawasan hutan konservasi Mawas yang terletak di bagian tenggara Provinsi Kalimantan Tengah merupakan zone inti (INPRES no. 2/2007) yang dikelola oleh Yayasan Borneo Orangutan Survival Fondation (BOSF) Mawas Kalimantan Tengah sejak tahun 2001 pada koordinat $114^{\circ} 25^{\prime \prime}-115^{\circ} 00^{\prime \prime} \mathrm{BT}$ dan $1^{\circ} 45^{\prime \prime}$ $2^{\circ} 16^{\prime \prime}$ LS.

Sampel lokasi dilakukan pada 5 (lima) desa yang berada di sekitar wilayah unit manajemen hutan konservasi Mawas. Desa-desa tersebut adalah Mantangai Hilir, Katunjung, Lawang Kajang, Madara, dan Batampang. Penentuan desa sampel dengan pertimbangan letak terhadap kawasan mawas, kerawanan kebakaran, dan sub suku dayak yang bermukim di desa tersebut (terdiri dari Dayak Ngaju (Dayak Kapuas), Ma'anyan, dan Bakumpay). Penentuan desa berdasarkan letak geografis dalam peta wilayah, tingkat kerawanan kebakaran, perbedaan sub suku Dayak dan kondisi pertanian.

\section{B. Bahan dan Alat}

Bahan-bahan yang digunakan dalam penelitian ini terdiri dari kuesioner. Perlengkapan utama di lapangan adalah speedboat dan klotok (perahu kecil bermesin) digunakan untuk menjangkau ke 5 (lima) desa terpilih (Desa Mantangai Hilir, Katunjung, dan Lawang Kajang, Desa Madara dan Batampang), kamera digital dan timbangan analitik.

\section{Rancangan Penelitian}

Penelitian ini dilakukan dengan metode survey (Nawawi, 1994) dengan pendekatan rancangan secara berjenjang ganda (multistage sampling). Terdapat 48 Desa di lokasi penelitian, sementara sebanyak 5 (lima) desa diambil sebagai sampel. Pengambilan sampel secara purposive dilakukan pada saat menentukan 5 (lima) desa contoh agar menggambarkan representativitas terhadap seluruh desa yang ada di sekitar kawasan hutan Mawas.

Teknik pengambilan sampel dalam satuan kelompoknya dilakukan secara acak dimana masing-masing desa diambil responden sebanyak 48 orang dengan pertimbangan keterwa- kilan antara 10-35\%. Jumlah responden seluruhnya adalah 240 orang. Responden dan sampel penduduk desa dibedakan menjadi 3 (tiga) kelompok mata pencaharian yaitu : (1) Petani ladang (PTL), (2) Penangkap/nelayan ikan (PI), dan (3) Mata pencaharian Non-Petani dan Non-Penangkap ikan (PLL) yang terdiri dari pegawai negeri, pedagang, pendulang emas, peternak, penarik kelotok, pengrajin rotan, petani rotan, dan tukang.

Sebagai data penunjang dalam penelitian ini diuji juga pengaruh sikap individu dari masyarakat terhadap kondisi kerawanan atau risiko kebakaran pada ladangnya. Risiko kebakaran diantaranya ditentukan oleh parameter muatan (bobot segar) bahan bakar dan tingginya (Saharjo, et al, 2000). Bahan bakar tersebut adalah berupa vegetasi yang tumbuh pada lahan ladang. Dengan menggunakan uji multivariat, akhirnya dapat diketahui adanya pengaruh atau tidak dari sikap responden terhadap kerawanan kebakaran. Ukuran jumlah sampel didasarkan pada pertimbangan interval kepercayaan antara $5-10 \%$ dengan mempergunakan tabel interval kepercayaan (Vockell, 1983) dengan rumus sebagai berikut :

$$
\frac{1,96 \sqrt{2.500}}{\sqrt{n}} \times \sqrt{\frac{N \quad n}{N 1}} \quad x 100 \%
$$

dimana: $1,96=$ Nilai $Z$ setara dengan taraf signifikansi $5 \%$

$2.500=$ Bilangan konstan

$\mathrm{n} \quad=$ Jumlah anggota sampel

$\mathrm{N}=$ Jumlah populasi

Uji validitas dalam penelitian ini mengikuti prosedur content validity dan construct validity (Nurgiyantoro et al. 2000). Content validity mensyaratkan adanya kesesuain antara instrumen dengan deskripsi masalah yang akan diteliti, sedangkan construct validity berhubungan dengan pertanyaan yang harus sesuai dengan konsep keilmuan kebakaran. Uji reliabilitas menggunakan teknik stabilitas yaitu dengan mencobakan sebuah instrumen lebih dari satu kali dalam waktu yang berbeda. Hasil keduanya dikorelasikan, dan jika korelasi $>50 \%$ maka instrumen dinyatakan reliable (Nurgiyantoro, 2000).

\section{Metode Pengumpulan Data}

Pengumpulan data dilakukan dengan wawancara mendalam (indepth interview) dan observasi lapangan di lima desa contoh. 
Informasi sumber-sumber api rutin lahan diperoleh dengan cara menanyakan pengalaman secara langsung kepada masyarakat yang dipandu dengan daftar pertanyaan terstruktur (quesioner). Demikian juga informasi respon masyarakat terhadap jenis-jenis aktivitas pencegahan dilakukan dengan cara yang sama dengan informasi sumber api.

Pengumpulan data wawancara mengikuti metode Muhadjir (1992) yaitu subyek mendatangi secara langsung responden dan mengambil kesempatan yang memudahkan. Responden yang diambil harus sesuai dengan kapasitasnya. Wawancara dilakukan dengan cara bertatap muka dengan responden sehingga diperoleh gambaran secara lengkap tentang obyek yang diteliti (Bungin, 2003) dan dilakukan secara formal dan informal sesuai dengan situasi yang dihadapi untuk menghindari adanya nonrespon error dan respon error. Pertanyaan yang dibuat bersifat open questions, multiple choice questions, dan dichotomous questions (Marzuki, 2005). Wawancara ditujukan kepada Kepala Keluarga (KK) yang umumnya pria, sedangkan jika dalam keluarga, suami sudah meninggal dunia maka isteri menggantikan kepala keluarga. Muatan bahan bakar dihitung dari bobot bahan bakar bawah ladang berupa vegetasi hidup dan mati termasuk serasah, yaitu dengan cara mengambil contoh bahan bakar per $\mathrm{m}^{2}$ sebanyak 4 (empat) kali yang dilakukan secara acak. Selanjutnya ditimbang berat segarnya dengan timbangan analitik.

\section{E. Analisis Data}

Analisis data penelitian lebih bersifat deskriptif dengan cara menarasikan semua fakta yang diperoleh di lapangan. Analisis sumber api lahan dilakukan dengan membuat nilai presentase dari jumlah responden yang menyatakan ada sumber api tertentu dari seluruh responden yang diwawancarai.

Analisis respon masyarakat terhadap inovasi pencegahan kebakaran dilakukan dengan menggunakan uji frekuensi Chi-square (uji independensi) untuk mengetahui pengaruh mata pencaharian terhadap sikap menerima atau tidak responden terhadap opsi pencegahan kebakaran yang ditawarkan (Gasperz, 1995, Singgih, 2001). Satuan dalam variabel yang diukur adalah jumlah orang (frekuensi) dalam kelompok responden yang telah merespon semua pertanyaan dan tawaran yang diberikan pewawancara.
Pertanyaan dan tawaran tersebut terdiri dari unsur pendidikan dalam prinsip pencegahan kebakaran hutan dan rekayasa teknologi untuk kepentingan pencegahan kebakaran. Variabel pendidikan yang ditawarkan terdiri dari 8 variabel yaitu : (1) Penyuluhan kontak langsung, (2) pelatihan dengan ceramah dan praktek, (3) penyuluhan dengan pemutaran film dan video,(4) pelajaran di sekolah, (5) pemberiam pesan lewat khotbah Jum'at di Mesjid atau khotbah di Gereja, (6) pemberian pesan melalui Tokoh-Tokoh Adat,(7) kampanye kebakaran lewat publikasi, dan (8) kampanye kebakaran melalui TVRI dan RRI.

Variabel rekayasa teknologi yang ditawarkan terdiri dari 8 variabel yaitu: (1) pembuatan sekat bakar, (2) reduksi bahan bakar, (3) pelaksanaan patroli bahaya kebakaran, (4) mengatur sistem pembakaran, (5) pembukaan lahan tanpa bakar (PLTB), (6) teknik pembakaran terkontrol, (7) pengembangan pola tanam agroforestry, (8) bantuan alat pemadam sederhana.

Tes independensi terdiri atas dua faktor yaitu kelompok matapencaharian dan respon (fokus kepada ingin mengetahui pengaruh kelompok matapencaharian terhadap sikap suka atau tidak suka dalam merespon setiap inovasi aktivitas pencegahan yang ditawarkan). Penghitungan Chi-square $\left(\mathrm{X}^{2}\right)$, data observasi tersebut diolah lebih lanjut untuk mendapatkan expected value atau nilai yang diharapkan dari data observasi dengan rumus sebagai berikut (Gaspersz, 1991; Singgih, 2001):

$$
\text { Eij } \frac{R i X C j}{N}
$$

Dimana $:$ Eij $=$ Nilai yang diharapkan pada baris ke-i kolom ke-j

$\mathrm{Ri}=$ Jumlah total baris

$\mathrm{Cj}=$ Jumlah total kolom ke- $\mathrm{j}$

$\mathrm{N}=$ Jumlah total sampel

Nilai $\mathrm{X}^{2}$ hitung akan dibandingkan dengan nilai $\mathrm{X}^{2}$ tabel prekuensi. Jika $\mathrm{X}^{2}$ hitung lebih besar daripada $\mathrm{X}^{2}$ tabel, maka berarti terjadi perbedaan antara nilai observasi (observation value) dengan nilai harapan (expected value). Analisis multivariat biasa digunakan untuk mengetahui hubungan variabel yang datanya berkatagori ordinal sebagai variable faktor atau kovariat dengan data kuantitatif berskala rasio untuk variable dependen (Priyatno. 2009). Data katagori ordinalnya adalah sikap masyarakat terhadap pelatihan kebakaran seperti tertera pada Tabel 1. 
Tabel(Table) 1. Observasi sikap masyarakat terhadap pelatihan kebakaran (Observation of people atitude on fire training

\begin{tabular}{|c|l|c|c|c|c|}
\hline \multirow{2}{*}{ No } & \multirow{2}{*}{$\begin{array}{c}\text { Observasi } \\
\text { Observation })\end{array}$} & \multicolumn{4}{|c|}{$\begin{array}{c}\text { Mata pencaharian } \\
\text { (Livelihood) }\end{array}$} \\
\cline { 3 - 6 } & $\begin{array}{c}\text { Respon/sikap } \\
\text { responden }\end{array}$ & $\begin{array}{c}\text { Petani } \\
(\mathrm{PTL})\end{array}$ & $\begin{array}{c}\text { Penangkap } \\
\text { ikan (PI) }\end{array}$ & $\begin{array}{c}\text { Non-petani\&Non- } \\
\text { penangkap ikan (PLL) }\end{array}$ & Total \\
\hline & Sikap & 1 & 2 & 3 & $\Sigma \mathrm{R} 1$ \\
\hline 1 & Suka & $\mathrm{O} 11$ & $\mathrm{O} 12$ & $\mathrm{O} 13$ & $\Sigma \mathrm{R} 2$ \\
\hline 2 & Tidak suka & $\mathrm{O} 21$ & $\mathrm{O} 22$ & $\mathrm{O} 23$ & $\mathrm{~N}$ \\
\hline & Total & $\Sigma \mathrm{C} 1$ & $\Sigma \mathrm{C} 2$ & $\Sigma \mathrm{C} 3$ & \\
\hline
\end{tabular}

Variabel dependennya yang berskala rasio adalah, tinggi bahan bakar $(\mathrm{cm})$, dan muatan bahan bakar $\left(\mathrm{gram} / \mathrm{m}^{2}\right)$. Kedua jenis variable tersebut digambarkan dalam skema berikut (Gambar 1). Asumsi analisis multivariat menurut
Priyatno (2009) dan Wijaya (2009) adalah data memiliki varian dan kovarian yang sama, untuk menguji ini dilakukan uji asumsi homogenitas yaitu uji Laven's dan uji kesamaan kovarian (Uji Box's).



Gambar(Figure) 1. Skema hubungan antara respon masyarakat dengan risiko kebakaran ladang (Scheme of correlation among society responses to arable land fire risk)

Uji multivariate ini terdiri dari Uji Pillai's Trace, Wilk's Lambda, Hotelling's Trace, dan Roys Largest Roat. Analisis data kualitatif dilakukan untuk menarasikan hasil-hasil analisis data baik yang bersifat kualitatif maupun yang kuantitatif. Analisis data kualitatif hasil penelitian kebakaran, sistematikanya mengikuti unsur-unsur prinsip dalam pencegahan kebakaran, sedangkan dalam masing-masing unsur, prosesnya melalui tahapan penyederhanaan data yang terdiri dari pengujian, pengkatagorian, pentabulasian, dan pengkombinasian bukti-bukti yang menunjukkan proposisi (Singarimbun, 1989; Yin, 2006, Suryabrata, 1998, Marjuki,
2005). Satu hal lagi dalam analisis data kualitatif adalah penampilan data (display data) yang impormatif setelah penyederhanaan (reduksi data).

\section{HASIL DAN PEMBAHASAN}

\section{A. Sumber-Sumber Kebakaran Lahan}

Sumber api lahan di 5 (lima) desa sekitar kawasan hutan mawas berdasarkan pengalaman responden cukup bervariasi seperti yang ditunjukan dalam Tabel 2. 
Tabel(Table) 2. Sumber-sumber api berdasarkan pengalaman responden (Land fire sources base on respondent experiences)

\begin{tabular}{|c|l|c|c|c|c|c|}
\hline \multirow{2}{*}{ No. } & \multirow{2}{*}{$\begin{array}{l}\text { Sumber Api } \\
\text { (Land fire sources) }\end{array}$} & $\begin{array}{c}\text { Mantangai } \\
\text { hilir }\end{array}$ & Katunjung & $\begin{array}{c}\text { Lawang } \\
\text { Kajang }\end{array}$ & Madara & Batampang \\
\hline 1 & Petani Ladang & 100 & 95,8 & 100 & 100 & 56,2 \\
\hline 2 & Penangkap ikan & 56,2 & 66,7 & 62,5 & 52,1 & 82,2 \\
\hline 3 & Pengayu & 0 & 0 & 4,2 & 0 & 10,4 \\
\hline 4. & Pendulang emas & 0 & 0 & 4,2 & 0 & 0 \\
\hline 5 & Petani rotan & 0 & 4,2 & 0 & 0 & 37,5 \\
\hline 6 & Pengrajin perahu & 4,2 & 0 & 0 & 0 & 4,2 \\
\hline 7 & Pencari HHBK & 10,4 & 4,2 & 0 & 0 & 8,7 \\
\hline 8 & Peternak sistem lepas & 0 & 0 & 0 & 0 & 0 \\
\hline 9 & Perokok & 4,79 & 0 & 0 & 0 & 0 \\
\hline
\end{tabular}

Pernyataan responden merupakan hasil pengalaman yang mereka alami langsung semasa hidupnya di desa masing-masing. Penangkap ikan atau nelayan ikan menghasilkan sumber api ketika mereka membersihkan kolam beje, dan kadang-kadang membuat api untuk memasak ikan hasil tangkapan. Aktivitas pembersihan beje tersebut hampir dilakukan secara rutin pada musim kering saat genangan air rawa mengalami surut. Upaya mempermudah pencarian beje-beje biasanya pencari ikan membersihkan vegetasi rumput dan semak dengan cara membakar seperti persiapan lahan di ladang.

Api biasanya digunakan juga untuk membersihkan lahan setelah ditebas. Perlakuan pembakaran paling banyak dilakukan pada saat ladang baru dibuka dari sisa hutan atau semak belukar. Sebagian besar penduduk memiliki disiplin dalam hal membakar, tetapi sebagian kecil sering lalai sehingga dapat menghasilkan api liar. Kearifan local pembersihan lahan yang diterapkan sebagian penduduk adalah tumbuhan ditebas terlebih dahulu, kemudian di rebahkan dan dikumpul ke tengah ladang, dibersihkan sekat bakar, baru kemudian dilakukan pembakaran. Setelah pembakaran dilanjutkan dengan pengontrolan dan pemadaman api sisa (bahasa dayak : menyimpuk atau ipanruk) Dengan demikian untuk cara terakhir tidak akan ada api liar.

Berdasarkan sistem rotasi, setelah ladang dibuka dari belukar, ladang hanya dapat digunakan antara 3-4 tahun. Setelah itu mereka berpindah ke tempat lain yang masih belukar dan subur, dan ladang yang lama ditanami karet (Hevea braziliensis). Perilaku ini mempunyai kesamaan dengan rotasi berladang berpindah di lahan kering NTT (Foenay, 1999), perbedaannya hanya pada tipe lahan, peladang di NTT melakukannya di lahan miring.

\section{B. Pendapat Masyarakat terhadap Inovasi Pendidikan}

Beberapa inovasi yang ditawarkan untuk meningkatkan pengetahuan dan kesadaran masyarakat telah mendapat respon dari masyarakat sekitar hutan. Tiga kelompok masyarakat yang merespon tawaran pola pencegahan dari aspek pendidikan terbagi kedalam petani ladang (PTL), penangkap ikan (PI), dan matapencaharian lain-lain (PLL) sesuai metodologi yang disebut terdahulu. 
Tabel(Table) 3. Pendapat responden tentang inovasi pendidikan (Respondent opinion about educational innovation)

\begin{tabular}{|c|c|c|c|c|c|c|c|c|c|}
\hline \multirow{3}{*}{ No. } & \multirow{3}{*}{$\begin{array}{c}\text { Jenis inovasi } \\
\text { (Kind of innovation) }\end{array}$} & \multicolumn{6}{|c|}{$\begin{array}{l}\text { Matapencaharian (orang) } \\
\text { (Livelihood) (person) }\end{array}$} & \multirow{3}{*}{$\mathrm{Xh}^{2}$} & \multirow{3}{*}{$X_{t}^{2}$} \\
\hline & & \multicolumn{2}{|c|}{ PTL } & \multicolumn{2}{|c|}{ PI } & \multicolumn{2}{|c|}{ PLL } & & \\
\hline & & Suka & $\begin{array}{c}\begin{array}{c}\text { Tidak } \\
\text { suka }\end{array} \\
\end{array}$ & Suka & $\begin{array}{l}\text { Tidak } \\
\text { suka }\end{array}$ & Suka & $\begin{array}{r}\text { Tidak } \\
\text { suka }\end{array}$ & & \\
\hline 1 & $\begin{array}{l}\text { Penyuluhan kontak } \\
\text { langsung }\end{array}$ & 73 & 7 & 77 & 3 & 66 & 14 & 8,6 & 5,99 \\
\hline 2 & Pelatihan kebakaran & 72 & 8 & 77 & 3 & 65 & 15 & 9,47 & 5,99 \\
\hline 3 & $\begin{array}{l}\text { Pesan Lewat } \\
\text { Khotbah,gereja, } \\
\text { tokoh adat }\end{array}$ & 66 & 14 & 71 & 9 & 76 & 4 & 6,26 & 5,99 \\
\hline 4 & $\begin{array}{l}\text { Pendidikan } \\
\text { Kebakaran dan } \\
\text { lingkungan di S D }\end{array}$ & 64 & 16 & 71 & 9 & 75 & 5 & 7,07 & 5,99 \\
\hline 5 & $\begin{array}{l}\text { Kampanye Film dan } \\
\text { video }\end{array}$ & 63 & 17 & 72 & 8 & 74 & 6 & 7,65 & 5,99 \\
\hline 6 & $\begin{array}{l}\text { Pesan pencegahan di } \\
\text { TVRI }\end{array}$ & 73 & 7 & 69 & 11 & 62 & 18 & 6,07 & 5,99 \\
\hline 7 & $\begin{array}{l}\text { Pesan lewat leaflet } \\
\text { dan brosur }\end{array}$ & 68 & 12 & 74 & 6 & 69 & 11 & 7,08 & 5,99 \\
\hline
\end{tabular}

Keterangan $($ Remarks $): \mathrm{PTL}=$ Petani ladang (arable land farmer $) ; \mathrm{PI}=$ Penangkap Ikan $($ fish fisherman $) ; \mathrm{PLL}=\mathrm{Pencaharian}$ Lain-lain (selain PTL dan PLL) (non PTL and PLL).

Hasil-hasil respon masyarakat terhadap inovasi pendidikan (Tabel 3) menunjukan bahwa perbedaan matapencaharian berpengaruh nyata terhadap sikap menerima atau menolak pola inovasi pendidikan pencegahan kebakaran yang ditawarkan yaitu antara hasil observasi dengan hasil yang diharapkan. Unsur-unsur pencegahan yang dipengaruhi oleh matapencaharian penduduk adalah penyuluhan kontak langsung, pelatihan pengendalian kebakaran, pesan pencegahan kebakaran melalui khotbah Jum'at, di Gereja, dan tokoh-tokoh adat, pendidikan ekstrakulikuler tentang kebakaran dan lingkungan di Sekolah Dasar, kampanye pencegahan kebakaran melalui pemutaran film dan video, kampanye pencegahan kebakaran di TVRI, dan pencegahan lewat leaflet dan brosur untuk desadesa sekitar hutan Mawas. Secara keseluruhan masyarakat bersedia menerima semua pola pencegahan kebakaran melalui pendidikan dan peningkatan kesadaran terhadap pentingnya mencegah kebakaran. Chandler et al. (1983) mengatakan bahwa jika 7 (tujuh) unsur pencegahan tersebut dapat diaplikasikan maka proses pencegahan kebakaran dapat berjalan menuju keberhasilan.

\section{Pengalaman Masyarakat tentang Penegakan Hukum Kebakaran}

Upaya penegakan hukum oleh pemerintah khususnya tentang kebakaran masih sangat lemah ditandai oleh belum pernah ada orang yang ditangkap atau dinasehati akibat pelanggaran pembakaran. Hal tersebut dinyatakan oleh $96,7 \%$ responden (Tabel 4). Hanya 3,3\% adanya peneguran atau nasehat untuk tidak melakukan pembakaran lahan sembarangan. Selanjutnya hanya $46,7 \%$ penduduk yang pernah mengikuti penyuluhan aturan pembakaran di 5 (lima) desa contoh, sedangkan $53,3 \%$ penduduk belum pernah memperoleh penyuluhan tentang aturan membakar lahan. Data tersebut di atas menunjukkan bahwa sosialisasi hukum oleh pemerintah tentang kebakaran dan penindakan pelanggaran pembakaran di desa-desa sekitar kawasan hutan Mawas masih nampak lemah. 
Tabel(Table) 4. Pengalaman masyarakat tentang penerapan hukum, mengikuti penyuluhan aturan, adanya patroli, dan keberadaan RPK di 5 Desa sekitar Hutan Mawas (Society experient about law enforcement, participate elucidation, patroli, existence of RKP in five villages around Mawas Forest)

\begin{tabular}{|l|c|c|c|c|c|c|c|}
\hline $\begin{array}{l}\text { Tingkat } \\
\text { pengalaman } \\
\text { (experient) }\end{array}$ & $\begin{array}{c}\text { Mantangai } \\
\text { Hilir }\end{array}$ & Katunjung & $\begin{array}{c}\text { Lawang } \\
\text { Kajang }\end{array}$ & Madara & Batampang & $\begin{array}{c}\text { Total } \\
\text { (orang) }\end{array}$ & $\begin{array}{c}\text { Persen } \\
(\%)\end{array}$ \\
\hline $\begin{array}{l}\text { Penerapan } \\
\text { hukum }\end{array}$ & & & & & & & \\
\hline Pernah & 1 & 1 & 0 & 2 & 4 & 8 & 3,3 \\
\hline $\begin{array}{l}\text { Tidak pernah } \\
\begin{array}{l}\text { Mengikuti } \\
\text { penyuluhan }\end{array}\end{array}$ & 47 & 47 & 48 & 46 & 44 & 232 & 96,7 \\
\hline Pernah & 25 & 36 & 5 & 16 & 30 & 112 & 46,7 \\
\hline $\begin{array}{l}\text { Tidak pernah } \\
\text { Ada patroli }\end{array}$ & 23 & 12 & 43 & 32 & 18 & 128 & 53,3 \\
\hline Ada & 30 & 32 & 34 & 9 & 41 & 146 & 60,8 \\
\hline Tidak ada & 18 & 16 & 14 & 39 & 7 & 94 & 39,2 \\
\hline $\begin{array}{l}\text { Keberadaan } \\
\text { RPK }\end{array}$ & & & & & & & \\
\hline Tahu & 34 & 38 & 43 & 39 & 43 & 197 & 82,1 \\
\hline Tidak Tahu & 14 & 10 & 5 & 9 & 5 & 43 & 17,9 \\
\hline
\end{tabular}

Pada bagian lain sekitar 60,8\% masyarakat telah mengetahui adanya kegiatan patroli lingkungan yang dimotori Regu Pengendali Kebakaran (RPK) di Desa pada musim kemarau. RPK merupakan organisasi sosial masyarakat yang telah berperan di dalam pengendalian api kecil hingga sedang di wilayah desa. Patroli lingkungan tersebut utamanya diarahkan untuk mencegah terjadinya kebakaran hutan dan lahan, sementara hanya $39,2 \%$ penduduk yang tidak mengetahui adanya kegiatan patroli lingkungan di musim kering. Dari sini nampak bahwa peran RPK di masyarakat telah dikenal. Kondisi tersebut lebih dikuatkan lagi dengan pengetahuan masyarakat tentang RPK Desa yang telah dikenal oleh $82,1 \%$ penduduk. Hanya $17,9 \%$ penduduk yang tidak mengenal adanya RPK. Atas dasar itu seyogyanya RPK di Desa perlu disinambungkan keberadaannya, dimantapkan programnya, dan dilengkapi peralatan pemadam kebakarannya oleh Pemerintah atau pihak pengelola.

\section{Respon Masyarakat terhadap Inovasi Rekayasa Teknologi}

Hasil survey menunjukan terdapat perbedaan nyata antara respon masyarakat hasil observasi dengan respon harapan di 5 (lima) desa contoh dalam hal menyukai pembuatan sekat bakar pencegah api liar pada ladang masing-masing. Api liar dimaksud adalah api baik yang dapat meloncat saat melakukan pembakaran terkendali (prescribe burning) maupun api liar yang datang dari luar lokasi ladang. Rata-rata 41 dari 48 responden $(85,4 \%)$ menyukai pembuatan sekat bakar karena penting untuk mencegah api liar. Hanya 14,6\% atau 7 dari 48 responden menyatakan tidak suka karena mereka menganggap sudah aman (Tabel 5). Sebagian besar penduduk menyukai melaksanakan pembersihan bahan bakar di ladang saat menjelang musim kemarau dan sistem pembakaran ladang secara bergiliran serta kegiatan patroli bahaya kebakaran dan lingkungan di desa pada saat musim kering. dengan alasan untuk menjamin keamanan ladangnya masing-masing dari tidak terkendalinya pembakaran dan menjaga kebiasaan yang sudah turun-temurun.

Berbeda dengan respon terhadap penerapan teknologi pencegahan kebakaran sebelumnya bahwa untuk sementara masyarakat sekitar hutan mawas sebagian besar 
tidak suka dengan melaksanakan pembukaan lahan tanpa bakar (PLTB) dengan alasan teknologi tersebut tidak praktis dan perlu banyak tenaga dan biaya. Demikian pula pola tanam campuran agroforestry sementara kurang diminati oleh sebagian besar penduduk dengan alasan jika didalam ladang ditanami jenis pohon hutan mereka khawatir ladangnya kembali menjadi hutan.

Tabel(Table) 5. Pendapat masyarakat tentang inovasi rekayasa teknologi (Society opinion about technology engineer inovation)

\begin{tabular}{|c|c|c|c|c|c|c|c|c|c|c|c|c|c|}
\hline \multirow{3}{*}{ No } & \multirow{3}{*}{ Jenis Inovasi } & \multicolumn{10}{|c|}{ Respoden Desa (orang) } & \multirow{3}{*}{$\mathrm{X}_{\mathrm{h}}^{2}$} & \multirow{3}{*}{$\mathrm{X}_{\mathrm{t}}^{2}$} \\
\hline & & \multicolumn{2}{|c|}{$\begin{array}{c}\text { Mantangai } \\
\text { Hilir }\end{array}$} & \multicolumn{2}{|c|}{ Katunjung } & \multicolumn{2}{|c|}{$\begin{array}{c}\text { Lawang } \\
\text { kajang }\end{array}$} & \multicolumn{2}{|c|}{ Madara } & \multicolumn{2}{|c|}{ Batampang } & & \\
\hline & & Suka & $\begin{array}{c}\text { Tidak } \\
\text { suka }\end{array}$ & Suka & $\begin{array}{c}\text { Tidak } \\
\text { suka }\end{array}$ & Suka & $\begin{array}{c}\text { Tidak } \\
\text { suka }\end{array}$ & Suka & $\begin{array}{c}\text { Tidak } \\
\text { suka }\end{array}$ & Suka & $\begin{array}{l}\text { Tidak } \\
\text { suka }\end{array}$ & & \\
\hline 1 & $\begin{array}{l}\text { Pembuatan } \\
\text { sekat bakar }\end{array}$ & 28 & 20 & 47 & 1 & 46 & 2 & 39 & 9 & 45 & 3 & 41,79 & 9,49 \\
\hline 2 & $\begin{array}{l}\text { Reduksi } \\
\text { bahan bakar }\end{array}$ & 27 & 21 & 46 & 2 & 44 & 4 & 41 & 7 & 47 & 1 & 44,50 & 9,49 \\
\hline 3 & $\begin{array}{l}\text { Patroli } \\
\text { kebakaran }\end{array}$ & 29 & 19 & 48 & 0 & 45 & 3 & 40 & 8 & 48 & 0 & 22,06 & 9,49 \\
\hline 4 & $\begin{array}{l}\text { Bakar } \\
\text { bergiliran }\end{array}$ & 26 & 22 & 46 & 2 & 43 & 5 & 39 & 9 & 45 & 3 & 39,22 & 9,49 \\
\hline 5 & PLTB & 22 & 26 & 15 & 33 & 17 & 31 & 19 & 29 & 7 & 41 & 11,41 & 9,49 \\
\hline 6 & $\begin{array}{l}\text { Pola tanam } \\
\text { agroforestry }\end{array}$ & 25 & 23 & 16 & 32 & 16 & 32 & 21 & 27 & 5 & 43 & 20,73 & 9,49 \\
\hline 7 & $\begin{array}{l}\text { Peringatan } \\
\text { dini }\end{array}$ & 43 & 5 & 48 & 0 & 48 & 0 & 43 & 5 & 48 & 0 & 15,65 & 9,49 \\
\hline 8 & $\begin{array}{l}\text { Bantuan alat } \\
\text { pemadam } \\
\text { sederhana }\end{array}$ & 48 & 0 & 44 & 4 & 47 & 1 & 48 & 0 & 42 & 6 & 13,48 & 9,49 \\
\hline
\end{tabular}

Berdasarkan Tabel 5, pada umumnya penduduk menyenangi adanya peringatan bahaya kebakaran dari pemerintah serta pengharaan
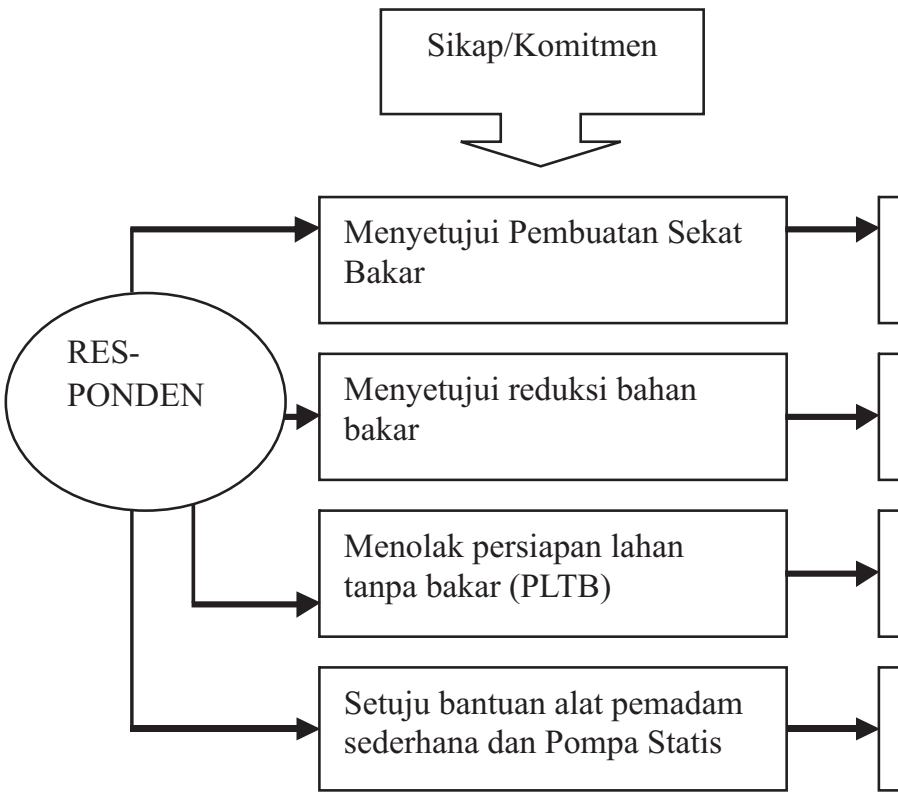

Mencegah api liar masuk ladang dan untuk pembakaran terkendali

Jika ada api mudah dimatikan

Membakar itu

praktis,murah\&mudah dikendalikan

Untuk pemadaman dini api liar di Desa

Gambar(Figure)2. Sikap responden terhadap inovasi rekayasa teknologi dan argumentasinya (Respondent's perception on engineering technology innovation and its argument) 


\section{E. Pengaruh Sikap Menerima Inovasi Pen- didikan terhadap Tinggi dan Muatan Bahan Bakar Ladang}

Data hasil observasi lapangan dan analisis multivariate menunjukan bahwa sikap responden berpengaruh sangat nyata terhadap tinggi dan muatan bahan bakar di ladangnya. Kelompok responden yang suka inovasi pendidikan/ penyuluhan ternyata memiliki ladang berbahan bakar lebih jarang (ringan) dan rendah dibandingkan dengan responden yang tidak suka dan sangat tidak suka dalam menerima penyuluhan/ pendidikan. Hal tersebut mengindikasikan bahwa kelompok masyarakat yang menerima inovasi berarti memang sudah berdisiplin dalam memelihara ladangnya. Melalui uji yang digunakan dengan asumsi homogenitas, Uji multivariate, dan dan uji hipotesis menggunakan program SPSS diperoleh hasil sebagai berikut :

\section{Uji homogenitas}

Asumsi pada analisis ini adalah bahwa data memiliki varian dan kovarian yang sama. Dengan menggunakan uji kesamaan varian Laven's untuk mengetahui kesamaan varian antara kelompok data, diperoleh bahwa signifikansi variabel tinggi bahan bakar adalah 0,084 dan muatan bahan bakar 0,587. Karena signifikansi $>0,05$, disimpulkan bahwa varian kelompok data adalah sama untuk kedua variabel tersebut, jadi asumsi homogenitas terpenuhi. Tabel 6 memperlihatkan data dasar sikap menerima dan tinggi serta muatan bahan bakar bawah ladang. Data statistik deskriptif dari sikap, tinggi, dan muatan bahan bakar disajikan dalam Tabel 7.

Tabel(Table) 6. Nilai sikap terhadap Inovasi dari penduduk hubungannya dengan tinggi dan muatan Bahan Bakar pada Ladang (Attitude value of the people on innovation having dial with fuel height and load)

\begin{tabular}{|c|c|c|c|}
\hline No & Sikap Menerima & Tinggi Bahan bakar $(\mathrm{cm})$ & Muatan Bahan Bak ar $\left(\mathrm{gram} / \mathrm{m}^{2}\right)$ \\
\hline 1 & 3 & 20 & 1.000 \\
\hline 2 & 1 & 155 & 1.250 \\
\hline 3 & 3 & 30 & 1.007 \\
\hline 4 & 3 & 25 & 1.005 \\
\hline 5 & 3 & 27 & 1.010 \\
\hline 6 & 2 & 70 & 1.100 \\
\hline 7 & 3 & 30 & 985 \\
\hline 8 & 2 & 75 & 1.100 \\
\hline 9 & 3 & 25 & 900 \\
\hline 10 & 1 & 130 & 1.205 \\
\hline 11 & 3 & 35 & 1.005 \\
\hline 12 & 2 & 55 & 1.110 \\
\hline 13 & 3 & 37 & 990 \\
\hline 14 & 3 & 40 & 985 \\
\hline 15 & 2 & 50 & 1.115 \\
\hline 16 & 3 & 40 & 995 \\
\hline 17 & 3 & 35 & 1.010 \\
\hline 18 & 3 & 40 & 1.000 \\
\hline 19 & 2 & 65 & 1.115 \\
\hline 20 & 1 & 110 & 1.230 \\
\hline
\end{tabular}

Keterangan $($ Remarks $):$ Suka $=3$, tidak suka $=2 ;$ sangat tidak suka $=1$ 


\section{Uji Multivariate}

Uji ini terdiri dari Pillai's Trace, Wilk's Lambda, Hotelling's Trace, dan Roys Largest Root (Tabel 8). Kriteria yang digunakan jika signifikansi $<0,05$ maka dapat disimpulkan bahwa ada pengaruh antara komitmen responden terhadap tinggi dan muatan bahan bakar ladangnya. Jika signifikansi $>0,05$ maka tidak ada pengaruh nyata antara sikap suka tidak suka terhadap kondisi bahan bakar. Dari Tabel 8 uji multivariate dapat diketahui bahwa signifikansi sikap menerima pendidikan semuanya lebih kecil dari 0,05 sehingga dapat disimpulkan bahwa ada pengaruh sikap/respon responden terhadap kondisi tinggi dan muatan bahan bakar.

Sikap-sikap masyarakat yang diperoleh dalam penelitian ini mencerminkan tingginya partisipasi masyarakat dalam ide dan implementasi pencegahan kebakaran hutan.

Tabel(Table) 7. Statistik deskriptif hubungan antara sikap menerima inovasi pendidikan dengan tinggi dan muatan bahan bakar ladang (Descriptive statistic of responden's atitude, fuel height and weight in the field)

\begin{tabular}{|l|l|c|c|c|}
\hline \multicolumn{2}{|c|}{$\begin{array}{l}\text { Sikap Menerima } \\
\text { Pendidikan }\end{array}$} & Mean & Std. Deviasi & N \\
\hline \multirow{4}{*}{ Tinggi BB } & Sangat tidak suka & 131,67 & 22,546 & 3 \\
\cline { 2 - 5 } & Tidak suka & 63,00 & 10,368 & 5 \\
\cline { 2 - 5 } & Suka & 32,00 & 6,809 & 12 \\
\cline { 2 - 5 } & Total & 54,70 & 37,174 & 20 \\
\hline \multirow{4}{*}{ Muatan BB } & Sangat tdk suka & $1.228,33$ & 22,546 & 3 \\
\cline { 2 - 5 } & Tidak suka & $1.108,00$ & 7,583 & 12 \\
\cline { 2 - 5 } & Suka & 991,00 & 30,003 & 20 \\
\cline { 2 - 5 } & Total & $1.055,85$ & 93,038 & \\
\hline
\end{tabular}

Keterangan : $\mathrm{BB}=$ bahan bakar

Faktor-faktor yang dapat mempengaruhi tinggi rendahnya partisipasi masyarakat adalah : jenis kelamin, umur, pendidikan, kedudukan, jumlah keluarga, dan luasnya lahan yang dimiliki reponden (Wijayanto, 1999). Hasil analisis ter- sebut sebagai pelengkap penelitian yang diperoleh dari penelitian partisipasi masyarakat dalam kegiatan reboisasi hutan lindung pasca kebakaran di lereng Gunung Merapi Yogyakarta.

Tabel (Table) 8. Uji multivariat pengaruh komitmen masyarakat terhadap tinggi dan muatan bahan bakar ladang (Multivariate test of community commitment on fuel haight and weight at the Field)

\begin{tabular}{|l|l|r|c|c|c|c|}
\hline Efek & & Nilai & F & $\begin{array}{c}\text { Hipotesis } \\
\text { df }\end{array}$ & Error df & Sig \\
\hline Intersep & Pillai's Trace & 0,999 & $12883,319(\mathrm{a})$ & 2,000 & 16,000 & 0,000 \\
\hline & Wilk's Lambda & 0,001 & $12883,319(\mathrm{a})$ & 2,000 & 16,000 & 0,000 \\
\hline & Hotelling's Trace & 1610,415 & $12883,319(\mathrm{a})$ & 2,000 & 16,000 & 0,000 \\
\hline & Roy's Largest Root & 1610,415 & $12883,319(\mathrm{a})$ & 2,000 & 16,000 & 0,000 \\
\hline $\begin{array}{l}\text { Sikap_Men } \\
\text { Pendidikan }\end{array}$ & Pillai's Trace & 1,216 & 13,196 & 4,000 & 34,000 & 0,000 \\
\hline & & & & & & \\
\hline & Wilks' Lambda & 0,032 & $36,949(\mathrm{a})$ & 4,000 & 32,000 & 0,000 \\
\hline & Hotelling's Trace & 22,736 & 85,261 & 4,000 & 30,000 & 0,000 \\
\hline & Roy's Largest Root & 22,386 & $190,283(\mathrm{~b})$ & 2,000 & 17,000 & 0,000 \\
\hline
\end{tabular}

Keterangan: $\mathrm{a}=$ Exact statistic

$\mathrm{b}=$ The statistic is an upper bound on $\mathrm{F}$ that yield a lower bound on the significance level $\mathrm{c}=$ Design: Intercept + Sikap_Men_Pendidikan 


\section{Uji Hipotesis}

Uji hipotesis digunakan untuk mengetahui ada tidaknya perbedaan tinggi dan muatan bahan bakar antara tingkat suka, tidak suka, dan sangat tidak suka dari responden terhadap inovasi pendidikan (Tabel 9).

Tabel (Table) 9. Uji hipotesis tinggi dan muatan bahan bakar ladang dengan tabel "Test of BetweenSubjects Effects" (Hypothesis test of fuel haight and weight of fields using test of between subject affects)

\begin{tabular}{|l|l|c|r|c|r|c|}
\hline Source & $\begin{array}{l}\text { Dependent } \\
\text { variable }\end{array}$ & $\begin{array}{l}\text { Type III Sum } \\
\text { of Squares }\end{array}$ & Df & $\begin{array}{c}\text { Mean } \\
\text { Square }\end{array}$ & F & Sig \\
\hline Corrected Model & Tinggi_BB & $24299,533(\mathrm{a})$ & 2 & 1249,767 & 105,560 & 0,000 \\
& Muatan_BB & $153315,883(\mathrm{~b})$ & 2 & 76657,942 & 116,892 & 0,000 \\
\hline Intercept & Tinggi_BB & 83315,315 & 1 & 83315,315 & 723,864 & 0,000 \\
& Muatan_BB & 17953211,53 & 1 & 17953211,5 & 27375,883 & 0,000 \\
\hline Sikap_Men_Pendidikan & Tinggi_BB & 24299,533 & 2 & 12149,767 & 105,560 & 0,000 \\
& Muatan_BB & 153315,883 & 2 & 76657,942 & 116,892 & 0,000 \\
\hline Error & Tinggi_BB & 1956,667 & 17 & 115,098 & & \\
& Muatan_BB & 11148,667 & 17 & 655,804 & & \\
\hline Total & Tinggi_BB & 86098,000 & 20 & & & \\
& Muatan_BB & 22460849,00 & 20 & & & \\
\hline Corrected Total & Tinggi_BB & 26256,200 & 19 & & & \\
& Muatan BB & 164464,550 & 19 & & & \\
\hline
\end{tabular}

Keterangan : $\mathrm{R}^{2}=0,925$ (Adjusted $\mathrm{R}^{2}=0,917$ )

$\mathrm{R}^{2}=0,932$ (Adjusted $\left.\mathrm{R}^{2}=0,924\right)$

Ho = Artinya tidak ada perbedaan tinggi dan muatan bahan bakar ladang antara ladang milik responden yang suka, tidak suka, dan sangat tidak suka inovasi pendidikan.

$\mathrm{Ha}=$ Artinya ada perbedaan tinggi dan muatan bahan bakar ladang milik responden dan yang suka,tidak suka, dan sangat tidak suka dengan inovasi pendidikan.

Berdasarkan hasil Test of Between-Subjects Effects (Tabel 9) tentang sikap responden, diketahui signifikansinya sebesar 0,000 atau lebih kecil dari 0,05. Dengan demikian bahwa hipotesis nol ditolak, dengan kata lain ada perbedaan antara sikap responden yang suka, tidak suka, sangat tidak suka inovasi pendidikan dalam hal tinggi dan muatan bahan bakar pada ladangnya akibat perbedaan intensitas pemeliharaan. Data lapangan menunjukkan bahwa mereka yang tidak setuju inovasi pendidikan ternyata memiliki ladang kurang terpelihara ditandai dengan muatan bahan bakar yang berat yang mencerminkan rapat dan tinggi. Jenis-jenis bahan bakar pada ladang umumnya berupa gulma didominasi paku-pakuan, teki-tekian, dan alang-alang. Hubungannya dengan api kebakaran sebenarnya bahan bakar di lahan gambut adalah termasuk lapisan gambut (Aswin, 2005).
Pengalaman dan opini masyarakat sekitar hutan tentang pengguna api lahan sangat diperlukan agar sasaran pembinaan ketertiban lingkungan dan pencegahan kebakaran lebih terarah dan efektif. Sekalipun menggunakan angkatan bersenjata (TNI/POLRI), kebijakan kehutanan dan manajemen hutan, sebagian besar pemerintah telah gagal mengelola hutan tanpa masyarakat lokal ikut terlibat di dalamnya (Suyanto et al., 2004). Keterlibatan masyarakat tersebut meliputi kepemilikan lahan yang jelas dan partisipasi masyarakat lokal.

Setiap mata pencaharian memiliki pandangan yang berbeda terhadap bahaya kebakaran. Dengan diketahuinya sumber-sumber penyebab kebakaran maka tindakan pembinaan dan penanggulangan akan lebih efektif (Suratmo, 2003, Chandler, 1983). Tidak mudah memperoleh informasi penyebab kebakaran adalah diperlukannya suatu pengakuan pelaku yang berkonsekuensi pada sanksi dalam menegakan hukum, kondisi ini. ditemui juga di Gambia (Dampha, 2001) dan di desa Wenyime, provinsi Yunan di China (Linchang, 2001). Cara pendekatan yang dilakukan untuk mengetahui sumber-sumber penyebab kebakaran adalah dengan cara menggali informasi sumber-sumber api lahan yang bersifat rutin setiap tahun. 


\section{KESIMPULAN DAN SARAN}

\section{A. Kesimpulan}

1. Sumber-sumber api utama lahan di masyarakat yang tertinggi adalah bersumber dari kegiatan petani ladang dan penangkap ikan.

2. Sebagian besar masyarakat tertarik melakukan pencegahan kebakaran hutan melalui pola-pola pendidikan dan penerapan rekayasa teknologi pencegahan kebakaran berupa peringatan dini dan bantuan alat pemadam sederhana (kisaran jumlah responden 42 - 48 orang per desa).

3. Regu Pengendali Kebakaran (RPK) yang telah terbentuk di desa telah diakui keberadaannya oleh sebagian besar masyarakat sehingga jika difungsikan sebagai lembaga kontrol kebakaran di tingkat desa tingkat keberhasilannya cukup tinggi.

\section{B. Saran}

1. Pencegahan kebakaran hutan rawa gambut berbasis masyarakat perlu segera diterapkan di setiap desa dan kampung sekitar hutan rawa gambut Kalimantan Tengah dan kawasan konservasi Mawas.

2. Regu Pengendali Kebakaran (RPK) perlu dijadikan lembaga kontrol yang bersifat partisipatif sehingga perlu dilakukan fasilitasi pembentukan RPK di seluruh desa dan kampung dan pembinaannya.

3. Seorang Penyuluh pertanian dan kehutanan atau seorang tenaga khusus sebagai fasilitator masyarakat (Community facilitator) diperlukan di setiap desa sebagai inovator dan mediator antara masyarakat dengan pihak pemerintah dan pengelola hutan.

\section{DAFTAR PUSTAKA}

Almami, Dampha. 2001. Menegement of Forest Fire Through the Involvement of Local Communities : The Gambia. Forestry Departement. PO Box 405. Banjul. The Gambia

Chandler, G. P. Cheney, P. Thomas, L. Trabaud, and D. Williams. 1983. Fire in Forestry. Forest Fire Management and Organisation. A Wiley-Intersciense Publicatgion. John Wiley \& Sons. New York.

Esthon L.Foenay.1999. Shifting Cultivation and Fire: A Challenge to NTT's Development.
Fire and Sustainable Agricultural and Forestry Development in Eastern Indonesia and Northern Australia. Aciar proceedings. Canbera.

Gaspersz. V. 1991. Metode Perancangan Percobaan untuk Ilmu-Ilmu Pertanian, Ilmu-Ilmu Teknik, dan Biologi. Hal. 439446.(472). Penerbit Armico. Bandung.

Heikkila T.V., R. Gronovist, and M. Jurveius. 1993. Hanbook on Forest Fire Control. Forestry Training Programme Publication 21. National Board of Education of The Government of Finland.

Karki, S. 2002. Community Involvement and Management of Forest Fires in Southeast Asia. Project Fire Fight Southeast Asia. Bogor.Indonesia. http://www.pffsea.com.

Lawrence, D. and W.H. Schlesinger. 2001. Change in Soil Phosphorus During 200 years of Shifting Cultivation in Indonesia. Ecology 82:2769-80.

Linchang, Z., W. Long., Zhao. Y., and L. Caizhen. 2001. Community-Base Forest Fire Management in Wenyime village, Sanchahe Township, Dayao Country, Chuxiong Yi Autonomous Prefecture. Yunnan Province, China. Center for Community Development Studies (CS), Yunnan, China.

Marbyanto. 2003. Pengembangan Program Pengelolaan Kebakaran Berbasis Masyarakat. Pengalaman Proyek IFFM di Kalimantan Timur. Prosiding workshop. Kerjasama SCKPFP-EU dan Pemda Kabupaten Banjar. Martapura.

Marjuki. 2005. Metodologi Riset. Panduan Penelitian Bidang Bisnis dan Sosial. Penerbit Ekonisia Kampus Fakultas Ekonomi UII. Yogyakarta.

Masihiro, Atsuko. and Sumantri. 1999. Mid-term Assessment of Participatory Green Belt Trials for Follow up development. International symposium. Impact of Fire and Human activities on Forest Ecosystem in the Tropics. TFRC-JICA. Samarinda.

Muhadjir, N. 1992. Metodologi Penelitian Kualitatif. Telaah Positivistik, Rasionalistik, Phenomenologik, Realisme Metaphisik. Penerbit Rake Sarasin. Yogyakarta. 
Nawawi, H. dan M. Martini. 1994. Penelitian Terapan. Penerbit Gajah Mada University Press. Yogyakarta (271 Hal).

Nurgiyantoro, B., Gunawan, dan Marzuki. 2000. Statistik Terapan untuk Penelitian IlmuIlmu Sosial. Gadjah Mada University Press. Yogyakarta. 357 Hal. (20-25).

Priyatno, D. 2009. SPSS Untuk Analisis Korelasi, Regresi, dan Multivariate. Penerbit Gaya Media. Hal 119-141 (162).

Puspitasari, DE. 2007. Aspek Hukum Penanganan Kebakaran Hutan di Indonesia. Mimbar Hukum. Vol.19 No.1.

Saharjo B.H. , Endang A., Husaeni, Kasno, and. Hiroyuki Watanabe. 2000. Management of Fuel and Fire in Preparing Land for Forest Plantation and Shifting Cultivation. ACIAR Proceedings. No.01. Canbera.

Saharjo B.H. 2004. Profil Daerah Potensial Penghasil Hotspot dan Sumbernya Menurut RTRWP di Provinsi Kalimantan Selatan periode Juni-Desember 2003. South and Central Kalimantan Production Forest Project (SCKPFP). Draft Prosiding Kampanye Pengendalian Kebakaran Hutan. Banjarmasin.

Singgih S. 2001. Aplikasi Excel dalam Statistik Bisnis. Hal. 121-159 (249). Penerbit P.T. Elex Media Komputindo. Kelompok Gramedia. Jakarta.

Sungarimbun, M. dan Effendi S. 1985. Metode Penelitian Survey. LP3ES. Jakarta.
Suratmo, F.G.; E.A. Husaeni, N. Surati Jaya. 2003. Pengetahuan Dasar Pengendalian Kebakaran Hutan. Pedoman Nasional Pengendalian Kebakaran Hutan. Fahutan IPB. 503 Hal (55-98). Bogor.

Suryabrata S. 1998. Metodologi Penelitian. P.T. Raja Grafindo Persada.115 hal. Jakarta.

Suyanto, S., Rizki Pandu Permana, Noviana Khususiyah, and Laxman Joshi. 2004. Land Tenure. Agroforestry Adoption, and Reduction of Fire Hazard in a Forest Zone $\therefore$ A Case Study from Lampung. Sumatra. Indonesia.

Tacconi, L. 2003. Fires in Indonesia, Causes, Costs and Policy Implications. Center For International Forestry Research (CIFOR). Booklet. Bogor. Indonesia.

Usup, Aswin.2006. Strategi Pencegahan dan Pengendalian Kebakaran Hutan dan Lahan Berbasis Masyarakat. Seminar Nasional tentang Pencegahan, Penanggulangan dan Penindakan Pelaku Pembakaran Hutan, Lahan dan Pekarangan, Palangka raya.

Vockell., Edwar, L. 1983. Educational Research. New York. Macmillan Publishing Co.

Wijaya, Tony. 2009. Analisis Structural Equation Modeling Menggunakan Amos. Penerbit Universitas Atma Jaya Yogyakarta. 196 hal.

Yin, R.K. 2006. Studi Kasus: Desain dan Metode (Edisi Revisi, Ed 7). Raja Grafindo Persada. Jakarta. 